\title{
Impact of Staff Training on the Performance of the Zanzibar Immigration Services Department
}

\author{
Suleiman Hassan Ussi ${ }^{1} \quad$ Haroonah Nsubuga ${ }^{2}$ \\ Abdalla Ussi Hamad $^{3}$ Rukkaya Wakif Muhammed ${ }^{3}$ \\ 1. MPA Student, Zanzibar University, P. O. Box 2440, Zanzibar \\ 2. Assoc. Prof. Faculty of Arts and Social Sciences, Zanzibar University, P. O. Box 2440, Zanzibar \\ 3.Lecturer, Faculty of Arts and Social Science, Zanzibar University, P. O. Box 2440, Zanzibar
}

\begin{abstract}
The main objective of this study was to assess the role of staff training on the performance of Zanzibar Immigration Services Department (ZISD). Quantitative approach was adopted in this study and data was analyzed through descriptive (frequencies, mean and standard deviation) and inferential analysis (multiple linear regression analysis) approaches. Simple Random and purposive sampling were used to select 150 Respondents. Data was collected through closed ended questionnaires. The study results showed that, staff training affects the performance of Zanzibar Immigration Services Department where 80 respondents equal to (53.3\%) replied that, training had very high effect on workers' performance, 37 (24.7\%) replied that, the effect was high. Then, the study analysed the quality of training being provided, good relationship with superior, good relationship with peers and recognition of the workers have positive impact on the performance of Immigration Services Department in Zanzibar. The study recommended that, the department should determine the training needs suitable for the achievements of organizational goals.
\end{abstract}

Keywords: Staff Training, Organizational Performance, Zanzibar Immigration Services Department

DOI: $10.7176 / \mathrm{JRDM} / 72-06$

Publication date: January $31^{\text {st }} 2021$

\section{Introduction}

There is much concern about the success of the institution in relation to the employee satisfaction. In achieving better organizational performance, it relies heavily on the work performance level of the employees (Mumin, 2017). Performance is a function of ability and motivational packages, where ability is comprised of the skills, training and resources required for executing a task and motivation is described as an inner force that drives individual to act towards something (Mumin, 2017). Any organization performance results in a more motivated work force that has the drive for higher productivity, quality, quantity, commitment and drive. Organizational performance is key development of any country. Motivational package is said to be an integral part towards organizational performance (Calder, 2017). As a result, a lot of theories and approaches have been developed in order to explain the nature of employees' motivation in organizations.

The motivational packages are very essential for organizations as every concern entails physical, financial and human resources to achieve the goals. It is through motivation that the human resources can be utilized by making full use of it (Brian, 2013). This can be done by building willingness in employees to work. This will help the enterprise in securing best possible utilization of resources. Thus, it results into increase in productivity, reduction of cost of operations and improving overall efficiency.

In Tanzania, the level of performance has been asserted to be on employees' actual skills and payment, but on the level of motivation, less attention has been ascertained. Therefore, productivity and retention of employees are considered as functions of employee working environment and nature of work load, (Lameck 2015). Motivation sources also exert influence on factors such as employee turnover as well as job satisfaction and organizational commitment, Mitchell, et.al., (2016). According to Armstrong, (2015), one of the most fundamental concerns when a company or organization wants to achieve good work performance is to understand how to motivate its employees. As such therefore, it is important to appreciate the factors that motivate people and how such factors are to be employed.

In Zanzibar, according to Zanzibar Immigration Services Department (ZISD) Report (2017), many employees there did quit the department for other jobs; for example, in 2013 (8) employees, 2014 (6) employees, 2015 (6) employees, 2016 (9) employees and 2017 (4) employees. The main consequences of their departure were poor production, de-motivation and inactiveness of staff. These might be a show of job dissatisfaction and thus prompted the researchers to focus on the issue of motivation at ZISD. Thus, public sector employers must motivate their employees to perform at the highest level of productivity and effectiveness and get "more for less" (Porter, 2013).

The influence of motivation on performance can be summarized in the following formula: Performance $=$ Ability $x$ Understanding of the task $x$ Motivation $x$ Environment. However, in order to perform well, employees need first to have the knowledge and skills that are required for the job. Then, they must understand what they are 
required to do and have the motivation to expand effort to do so. And last, employees need to work in an environment that allows carrying out the task. For example, by the allocation of sufficient resources this is stated by Mitchell (2010).

\section{Research Motivation}

Many organizations especially public organizations have for a long time been blamed for having poor staff motivation schemes resulting into poor work execution. Hence, it fails to achieve their goals. The problem is that, motivating public employees is easier said than done. Public workers have the reputation of being lazy and sluggish. Organizational performance is a major issue in the public sector for any country to develop; staff training as a motivation strategy is crucial towards organizational effectives. Without training, those (staff), normally, they will not put up their best and the organization performance would be at stake (Halepota 2014).

Between 2018 and 2019, there were three (3) and two (2) employees respectively who left the Immigration Department (ZISD Report, 2019). This was due to poor motivational packages including but not limited to training of staff in the department. This implies that, staff training should be accorded much attention. However, the assessment of the role of staff training on work execution in Zanzibar has not been cited by many researchers. This is why this study attempted to fill this gap focusing at Zanzibar Immigration Services Department (ZISD).

\section{Theatrical review}

The researchers used Abraham Maslow's Hierarchy of Needs Theory to inform the study.

Maslow (1943) was the first to use people's needs in motivation theory. He worked with individuals having neurotic ailments and assessed their hierarchy of needs. The hierarchy of needs is Physiological needs, Safety needs, Love needs, Esteem needs and Self-Actualization Needs. To be held in esteem both by themselves and by others. This kind of need produces such satisfaction as power, prestige, status and self-confidence. It includes both internal esteem factors like self-respect, autonomy, achievements and external esteem factors such as status, recognition and attention. Employees in this category try to maximize their knowledge, skills and performance to excel at service provision.

\section{Empirical Literature Review}

There are extensive empirical studies in relation to motivation and its roles on work execution. The following are the most selected empirical studies which are related to the subject matter of this study.

Chatzopoulou (2015), the survey took place in April 2014. During this time, Greece was experiencing an economic recession. The study was conducted through a structured questionnaire. The sample consisted of (85) employees of Local Authority. The survey revealed that, the most important motivating factors for Local Authority employees were training, interesting work, equal and fair treatment, good working relationship with supervisors and colleagues, objective assessment and good salary.

A study carried out by Aarabi (2013) on firm resources and sustained competitive advantage revealed that, the level of performance of employees relies not only on their actual skills but also on the level of motivation each person exhibits. The study used qualitative and quantitative methods (mixed approach). A stratified random sampling was used and 248 employees were targeted as study sample to the entire population. Thus, the report revealed that, motivation is an inner drive or an external inducement to behave in some particular way, typically, a way that will lead to rewards. Also Management has to ensure that employees are well motivated to curb the rate at which employees embark on industrial unrest which affect performance and employees are to comply with health and safety rules because the industry contribute hugely to the Gross Domestic Product (GDP) of any country.

According to Omollo (2015), who conducted a study on effect of motivation on employee performance of commercial banks in Kenya. Data was collected using questionnaires administered to selected employees. Data was analyzed using Microsoft Excel 2003, integrated package of personal computer and SPSS software. It was confirmed that, indeed job enrichment significantly affects job performance and that a good working environment and an average workload would highly motivate the employees to perfect their duties. Also observation of the study was that money is not the only motivator and it is not the primary motivator for everyone. Nevertheless, there is overwhelming evidence that, money is an important motivator for most people.

\section{Methodology}

Under this section, the researchers used positivism as the philosophical assumption for this study for two main reasons notably; it fits the quantitative research design used in this study. Also, there was need to use the method and philosophy that fit together the in-sights provided by quantitative research into a workable solution. Therefore, the quantitative research design was employed in this study since it allows the researchers to explore, explain a phenomenon and interpret data statistically in a wider and easy way.

For data collection and analysis, questionnaire was developed based on a Likert scale because it included questions which required the respondents to indicate how much or to what extent they agreed or disagreed with 
given statements on each construct. Following this type of rating scale, the options were ranging from lowest to highest responses. These options were; strongly disagree $(\mathrm{SD})=1$, disagree $(\mathrm{D})=2$ neutral $(\mathrm{N}) 3$, agree $(\mathrm{A})=4$, strongly agree $(\mathrm{SA})=5$.

Stratified random sampling was used to distribute 150 questionnaires to the respondents and all were collected. Respondents were classified by gender, age, marital status, education and work experience. Cronbach's Alpha test was conducted to measure the reliability of the instrument for all items and the result was 0.730 indicating a satisfactory level of internal consistency. Both descriptive and inferential statistical tools of analysis were used to analyses data collected. The descriptive statistics such as frequencies, mean and standard deviation as well as inferential statistics such as standard and hierarchical multiple regressions were used.

\section{Study Findings}

\subsection{Profile of the Respondents}

In social sciences, research personnel characteristics of respondents have very significant role to play in expressing and giving the responses about the problem of under investigation. This study therefore examined a set of personal characteristics namely; age, gender, education, marital status and work experience of the 150 respondents. These are seen in Table 1.

Table 1 Demographic of the respondents

\begin{tabular}{|l|l|l|l|}
\hline Variable & Category & Frequency & Percentage (\%) \\
\hline \multirow{4}{*}{ Gender } & Male & 80 & 53.0 \\
& Female & 70 & 47.0 \\
& $21-30$ & 28 & 18.7 \\
Marital Status & $31-40$ & 50 & 33.3 \\
& $41-50$ & 60 & 40.0 \\
& $51-60$ & 12 & 08.0 \\
& Married & 77 & \\
& Single & 27 & 51.3 \\
Education & Divorced & 21 & 18.0 \\
& Widow & 25 & 14.0 \\
& & & 16.7 \\
& Form six & 24 & 16.0 \\
& Certificate & 20 & 13.3 \\
& Diploma & 26 & 17.3 \\
& Degree & 50 & 33.3 \\
& Postgraduate & 30 & 20.1 \\
& & & \\
Work experience & Below 1 year & 5 & 3.3 \\
& 1-5 years & 52 & 34.7 \\
& 6-10 years & 46 & 30.7 \\
& 11-15 years & 37 & 24.7 \\
& 16-20 years & 10 & 6.6 \\
& & \\
\hline
\end{tabular}

Source: Researchers, 2020

Table 1 summarizes the demographic information of the respondents. Expectedly, the number of male employees at the Immigration Department is almost the same with the number of female employees. This distribution helped to avoid gender sample bias in the data. The age of the respondents in social research is one of the most important characteristics in capturing their views about a particular problem (Abideen 2010). The results in Table 1 suggest that, $73.3 \%$ of the respondents are between the age range of $31-50$, which is more than half of the total respondents. This indicates that, most of the employees are economically active labor force and they can manage well work responsibility.

More importantly, more than half of the respondents; $51.3 \%$ were married, $18 \%$ were single, $16.7 \%$ were widows and 14\% were divorced. The average respondents were found from late adolescent age group which is normally comprised either of persons who get married and took over the responsibility at their work places effectively.

It is observed in Table 1 that, half (53.4 percent) of the employees in the department were educated from degree and above whereas the remaining portion of the employees were only holders of certificate, Form Six and Diploma certificates. Such people need motivation so as to improve their knowledge in the department and the kind of motivation is training. 
Last but not the list, Table 1 also shows that, the employees at the Immigration Department have a rich work experience. Surprisingly, overwhelming number of employees; $62 \%$ have experience ranging from 6 to 20 years. This implies that, training as a motivational package is grossly needed to boost department performance.

\subsection{Empirical Findings}

The study aimed at accessing the effect of staff training and development on the performance of the Immigration Department in Zanzibar. The descriptive and inferential analysis were done to find out if there were staffs who received training and how they use their skills obtained from training at their respective work places and how such competencies have translated into increased departmental performance.

\subsubsection{Descriptive finding}

The employees were asked three questions in order to identify the status of staff training at the Zanzibar Immigration Department

\section{a) Types of Training Provided in your Organization}

In this part of the objective, the respondents were asked to mention the types of training that are most provided by their organization. The results are illustrated in Table 2

Table 2: Types of training effected by the organization

\begin{tabular}{|l|l|l|}
\hline Types of Training & Frequency & Percentage \\
\hline On the job training & 90 & 60.0 \\
\hline Off the job training & 32 & 21.3 \\
\hline Both of them & 28 & 18.7 \\
\hline Total & $\mathbf{1 5 0}$ & $\mathbf{1 0 0 . 0}$ \\
\hline
\end{tabular}

Source: Field Data, 2020

The results from Table 2 summarized the findings on the types of training effected by the organization. The results show that, 90 respondents out of 150 equal to $(60 \%)$ responded on the job training type. 32 equal to $(21.3 \%)$ replied off the job training and 28 equal to $(18.7 \%)$ relied both of them. Therefore, due to these results, it is clear that, the most common type of training provided by the organization is on the job training since more than $50 \%$ of the respondents replied to this effect.

These results are supported by the results from the study conducted by Nassazi (2013) about the "Effects of training on employee performance in Uganda". Where her results indicated that, a large number of her respondents were selected to participate. Thus, receiving training on job training. This proportion of respondents is represented by $(33.3 \%)$. As would be expected in many cases, 34 respondents were selected for training under the criteria of all employees going through the training and this is represented by a $(28.3 \%)$. However, she explained that, other employees were selected based on their supervisor's recommendation.

b) Selection of Workers to participate in the Training In this part of the objective, the researchers asked the respondents about the methods or mode used to select the workers to participate in training. The findings are explained clearly in Table 3.

Table 3: Mode of Selecting Workers to Participate in the Training

\begin{tabular}{|l|l|l|}
\hline Modes of Training & Frequency & Percentage \\
\hline On joining the company & 32 & 21.3 \\
\hline Supervisor's recommendation & 68 & 45.3 \\
\hline Compulsory for all employees & 17 & 11.3 \\
\hline Upon employee request & 17 & 11.3 \\
\hline Performance appraisal & 16 & 10.7 \\
\hline Total & $\mathbf{1 5 0}$ & $\mathbf{1 0 0 . 0}$ \\
\hline
\end{tabular}

Source: Field Data, 2020

Table 3 summarized the findings on the modes employed for the workers to be selected to participate in the training at their work place. The results showed that, 32 respondents equal to $(21.3 \%)$ were selected at the time of joining the company, 68 (45.3\%) were selected through supervisor's recommendation. 17 (11.3\%) replied that, it is compulsory for all workers. $17(11.3 \%)$ responded that, it is upon employee's request and $16(10.7 \%)$ replied that, it is due to the performance appraisal. These study results clearly indicate that, most of respondents who participated in training were through supervisor's recommendation.

Aidah (2013) in her study about "the effects of training on employee performance in Uganda" support the results of this study. The results indicate that, most of these respondents were selected to participate and thus, received training on joining the company. This proportion of respondents is represented by (33.3\%). As it would be expected in many cases, 34 respondents were selected for training under the criteria of all employees going through the training and this is represented by $(28.3 \%)$.

c) Duration of Providing Training in the Organization

In this part of objective, the researchers asked the respondents to identify the proper duration used by the 
organization to provide training. The results are portrayed clearly in Table 4.

Table 4: Duration used to provide Training

\begin{tabular}{|c|c|c|}
\hline Duration of Training & Frequency & Percentage \\
\hline Quarterly & 23 & 15.3 \\
\hline Every six months & 25 & 16.7 \\
\hline Once a year & 78 & 52.0 \\
\hline Every two years & 24 & 16.0 \\
\hline Total & $\mathbf{1 5 0}$ & $\mathbf{1 0 0 . 0}$ \\
\hline
\end{tabular}

Source: Field Data, 2020

Table 4 indicates the most duration where workers undergo training at their work place. The results showed that, 23 respondents equal to $(15.3 \%)$ replied that, they undergo training quarterly, while those who said they undergo training every six months were $25(16.7 \%)$. 78 respondents equal to $(52 \%)$ responded that, they undergo training once a year and $24(16 \%)$ said every two years. Therefore, it is clear that, training is done once a year since majority of the respondents replied to this effect.

\subsubsection{Inferential findings}

In this section, multiple linear regressions was used to identify the effect of staff training on the Immigration Department in Zanzibar.

The results of standard multiple regression as displayed in Table 5 indicated that, the independent variables quality of training being provided, good relationship with superior, good relationship with peers and recognition of the workers accounted for $63.8 \%$ of the variability in the performance of this Department in Zanzibar $\left(\mathrm{R}^{2}=\right.$ 0.638 ). The adjusted $\mathrm{R}$ square value was 0.622 .

Therefore, these findings imply that, only $62 \%$ of variability in regard to the performance of the Immigration Department could be explained by factors like quality of training being provided, good relationship with superior, good relationship with peers and recognition of the workers. The remaining $38 \%$ of variability depend on other unexplained factors. P- Value at 0.000 (Less than 0.05) insinuates that the Zanzibar Immigration Department performance significance model is at $5 \%$.

Table 5: Model Summary

\begin{tabular}{l|lllll}
\hline $\mathrm{R}$ & R Square & $\begin{array}{l}\text { Adjusted R } \\
\text { Square }\end{array}$ & $\begin{array}{l}\text { R Square } \\
\text { Change }\end{array}$ & $\begin{array}{l}\text { F } \\
\text { Change }\end{array}$ & $\begin{array}{l}\text { Sig. } \\
\text { Change }\end{array}$ \\
\hline $.796^{\mathrm{a}}$ & .638 & .622 & .618 & 40.115 & 0.000 \\
\hline
\end{tabular}

a. Predictors: (Constant), quality of training being provided, good relationship with superior, good relationship with peers and recognition of the workers

b. Dependent Variable: Immigration Department performance

Furthermore, Table 6 displays the coefficients' columns for the standard multiple regressions conducted.

Table 6: Coefficients of regression equation

\begin{tabular}{|c|c|c|c|c|c|c|}
\hline \multirow[t]{2}{*}{ Mode } & & \multicolumn{2}{|c|}{ Unstandardized Coefficients } & \multicolumn{2}{|c|}{$\begin{array}{l}\text { Standardized } \\
\text { Coefficients }\end{array}$} & \multirow[b]{2}{*}{ Sig. } \\
\hline & & $\mathrm{B}$ & Std. Error & Beta & & \\
\hline \multirow[t]{5}{*}{1} & (Constant) & .440 & .428 & & .870 & .554 \\
\hline & Quality of Training Being Provided & .594 & .087 & .207 & 3.978 & .000 \\
\hline & Good Relationship with Superior & .330 & .074 & .285 & 3.112 & .011 \\
\hline & Good Relationship with Peers & .020 & .009 & .020 & 2.234 & .000 \\
\hline & Recognition of the Workers & .087 & .098 & .323 & 2.263 & 0.02 \\
\hline
\end{tabular}

a. Predictors: (Constant), quality of training being provided, good relationship with superior, good relationship with peers and recognition of the workers

b. Dependent Variable: Immigration department performance

With reference to Table 6 , at the 0.05 level of confidence, the study revealed that, four predictors (quality of training being provided, good relationship with superior, good relationship with peers and recognition of the workers) had a significant effect or impact on the outcome variable (Immigration Department performance). In other words, the results of predictor variables as seen in Table 6 are as follows; quality of training being provided $(\beta=0.207, \mathrm{t}=3.978, \mathrm{p}<0.05)$, good relationship with superior $(\beta=0.285, \mathrm{t}=3.112, \mathrm{p}<0.05)$, good relationship with peers $(\beta=0.020, \mathrm{t}=2.234, \mathrm{p}<0.05)$, recognition of the workers $(\beta=0.0 .323, \mathrm{t}=2.263, \mathrm{p}<0.05)$.

Basically, the effect of quality of training being provided, good relationship with superior, good relationship with peers and recognition of the workers on performance of Immigration Department in Zanzibar was in a positive direction. This situation indicates that, the increase of scores in these predictor variables results in the increase of scores in the outcome variable. (Hair et.al., 2010, Pallant, 2016). This condition entails that, employees who have quality of training being provided, good relationship with superior, good relationship with peers and recognition 
of the workers tend to perform their job better. Therefore, these findings provide the opportunities for boards of directors and management of the public corporations in Zanzibar to improve their employees' performance by providing better training for their employees.

Moreover, these findings are are consistent with several other studies that investigated the effects of motivational packages on organizational perforamce. For example, Chatzopoulou (2015) revealed that, the most important motivating factors for Local Authority performance were interesting work, staff training, equal and fair treatment, good working relationships with supervisors and colleagues, objective assessment and good salary.

\section{Conclusion}

On examining and assessing how staff training affect the performance of Zanzibar Immigration Services Department, most of the respondents agreed on the job training as the major type of training provided in the organization, almost made $90(60 \%)$. Also, most respondents were selected on supervisor's recommendation as the mode of selecting workers to participate the Training sessions and this made 68 (45.4\%). Then, majority of the respondents replied concerning duration providing training in organization and explained that, training provided once a year which made 78 (52\%). Apart from that, majority of respondents replied good and excellent on the quality of training being provided in the organization which was equal to 87 (58\%) and 29 (19\%) respectively. On the effects of staff training on work execution, it was revealed that, quality of training being provided, good relationship with superior, good relationship with peers and recognition of the workers have positive impact on the performance of Immigration Department in Zanzibar.

\section{Recommendations}

Immigration Department should establish a specific training section in order to ensure that, program is carefully planned, coordinated and put into practice. Proper training and development process and procedures as required. The Departments of Administration and Human Resource Management should be responsible for designing and managing the training programs.

The Department also should determine the Training Needs suitable for the achievement of organizational goals. This also should be done by HR personnel in cooperation with the directors of other departments.

Besides this, it is also recommended that, the training goals should be specific, tangible, verifiable, timely and measurable and the objectives should be clear to both directors and employees because they can be used to evaluate their success on the services provided.

\section{References}

Armstrong, (2015) The Motivation to Work; 2nd edition, John Wiley, UK.

Alwadaei, S. A. (2010). Employee's perception of and satisfaction with performance appraisal System. International Journal of Service Industry Management, 14(2), 17-33.

Brian, T. (2013). The Four Factors of Motivation, Retrieved from BrongAhafoEducation Directorate. Kwame Nkrumah University, 19.

Bolman and Lucia (1997), Antecedents of Public Service Motivation;Journal of PublicAdministration Research and Theory 7 (2) 181-197.

Calder (2017) Industrial / Organizational Psychology: An Applied Approach, Fifth Edition, Thomas Learning Inc., Belmont CA. USA.

Carmines, B and Zeller, A (1979) Primary and Secondary data collection methods.Macmillan. New York

Lameck, J. (2015). The role of motivation on employee performance in the public sector: a case study of Bariadi district council(Doctoral dissertation, Mzumbe University).

Dubrin, (2002) Toward a Public Administration Theory of Public Service Motivation: An Institution Approach; Public Management Review, Sage Publications, UK.

Helepota (2005), Perceptions of public versus private sector personnel and informal red tape: Their impact on motivation. American Review of Public Administration, 20, 7-28. MA Publishers USA.

Helepota, H. A. (2014), Motivation Theories and their Application in Construction Cost Engineering, Vol. 47, No. $3 \mathrm{pp} \mathrm{4-35.}$

Hornby (2000), Motivation Theories and their Application in Construction Cost Engineering, Sage Publications, UK

Juma (2017), Public versus private employees: Debunking stereotypes. Review of Personnel Adminastration 11 (2), 1-27.

Jibowo, A.A. (2007)." Effect of Motivators and hygiene factors on job performance among extension workers in the former Western State of Nigeria". The quarterlyjournal of Administration, 12 (1): 45-54.

Kendra, C (2012) Theories of Motivation: A closer look at some important theories of motivation, www.about.com, retrieved on Monday, 28th January, 2013

Kothari, C (2004). Research Methodology Methods and Techniques.New Age International Publishers.Dharmesh 
Art Process. India.

Llopis, G. (2012). The top 9 things that ultimately motivate employees to achieve. Forbes, April, 6, 2012. UK

Maslow (1943), Abraham Maslow, Personalities Theories (online).Webspace.com. Available from: http:// websapace.ship.edu/cgboer/ maslo.html (access) 2011, March 4th

Matteson. (1999), Toward a Public Administration Theory of Public Service Motivation: An Institution Approach; Public Management Review 9(4) 545-5560xford University Press: UK.

May, T (2001) Social Research: Issues, methods and process: 3rd Ed; London, Independent International Publishers. UK.

Mohammad SaeidAarabi, (2013), Relationship between Motivational Factors and Job Performance of Employees in Malaysian Service Industry, Asian Social Science; Malaysia.

Mumin O, (2017). "The Role of Motivation on Employee Performance in Public Organization" A Case of Ministry of National Development Planning, Hargeisa, Somaliland. Munich,

Mullins and Laurie, (2010). Management \& organizational Behavior, 9th Edition, Harlo Financial time Prentice Hall

McGregor, D. (1960), The Human side of the Enterprise; McGraw-Hill, UK.Mifflin Company, New York.

Ministerial Statement (2016) Government of United Republic of Tanzania.A study of public sector accounting in Tanzania. Critical Perspectives on Accounting, 40, 8-25

Mitchell and Murm (2016), Motivation of Health care workers in Tanzania: A Case Study of Muhimbili National Hospital.East African Journal of Public Health Vol 5 No1.Nyati Publishers, Dar es Salaam. Tanzania.

NaimIsmajli.,(2015). The Importance of Motivation Factors on Employee Performance in Kosovo Municipalities, Published by University for Business and Technology, LagjaKalabria, 10000 Prishtine, Kosovo.

Ovidiu-IliutaDobre, (2013) Employee motivation and organizational Performance, Review of Applied SocioEconomic Research, (Volume 5, Issue 1/ 2013), ISSN: 2247-6172; ISSN-L: 2247-617

Pamela AkinyiOmollo, (2015). Effect of motivation on employee performance of commercial banks in Kenya: A case study of Kenya Commercial Bank in Migori.International journal of human resource studies, 5(2), 87103.

Richard, B (2014). The effect of motivation on employees' performance: empirical evidence from the BrongAhafo Education Directorate. Department of Managerial Science.Kwame Nkrumah University, 19

Said, N. S. M., Zaidee, A. S. E. A., Zahari, A. S. M., Ali, S. R. O., \&Salleh, S. M. (2015). Relationship between employee motivation and job performance: A study at UniversitiTeknologi MARA (Terengganu). Mediterranean Journal of Social Sciences, 6(4), 632.

Wellins RS (2015) Employee Engagement: The key to realizing competitive advantage. Development Dimensions International, 5, 1-31

Waiyaki, E. W. ( 2017). "Effect of Motivation on Employee Performance: a Case of pam Golding Properties limited, Nairobi” United States International University- Africa, Nairobi

Zanzibar Services Immigration Department Report (ZSID) (2017). Joint external evaluation of IHR core capacities of the United Republic of Tanzania-Zanzibar: mission report, 22-28 April 2017 